\title{
Enhanced Precipitation Variability Effects on Water Losses and Ecosystem Functioning: Differential Response of Arid and Mesic Regions
}

Osvaldo E. Sala ${ }^{1,2,3,}$, Laureano A. Gherardi ${ }^{1,3}$, Debra P.C. Peters ${ }^{3,4}$

${ }^{1}$ School of Life Sciences, Arizona State University, Tempe, AZ, 85287-4501, USA

${ }^{2}$ School of Sustainability, Arizona State University, Tempe, AZ, 85287-4501, USA

${ }^{3}$ Jornada Basin Long Term Ecological Research Program, New Mexico State University, Las

Cruces, NM, 88003, USA

${ }^{4}$ USDA-ARS, Jornada Experimental Range, Las Cruces, NM 88003, USA

* Corresponding author: Osvaldo Sala, Ph 480-965-4120, Fax 480-727-7584 Email address

Osvaldo.Sala@ASU.edu

Key words: enhanced precipitation variability, transpiration, soil evaporation, deep percolation, arid regions, climate change, ecosystem functioning 


\begin{abstract}
Climate change will result in increased precipitation variability with more extreme events reflected in more frequent droughts as well as more frequent extremely wet conditions. The increase in precipitation variability will occur at different temporal scales from intra to interannual and even longer scales. At the intra-annual scale, extreme precipitation events will be interspersed with prolonged periods in between events. At the inter-annual scale, dry years or multi-year droughts will be combined with wet years or multi-year wet conditions.

Consequences of this aspect of climate change for the functioning ecosystems and their ability to provide ecosystem services have been underexplored. We used a process-based ecosystem model to simulate water losses and soil-water availability at 35 grassland locations in the central US under 4 levels of precipitation variability (control, $+25,+50+75 \%$ ) and six temporal scales ranging from intra- to multi-annual variability. We show that the scale of temporal variability had a larger effect on soil-water availability than the magnitude of variability, and that inter- and multi-annual variability had much larger effects than intra-annual variability. Further, the effect of precipitation variability was modulated by mean annual precipitation. Arid-semiarid locations receiving less than about $380 \mathrm{~mm} \mathrm{yr}^{-1}$ mean annual precipitation showed increases in water availability as a result of enhanced precipitation variability while more mesic locations $(>380 \mathrm{~mm}$ $\mathrm{yr}^{-1}$ ) showed a decrease in soil water availability. The beneficial effects of enhanced variability in arid-semiarid regions resulted from a deepening of the soil-water availability profile and a reduction in bare soil evaporation. The deepening of the soil-water availability profile resulting from increase precipitation variability may promote future shifts in species composition and dominance to deeper-rooted woody plants for ecosystems that are susceptible to state changes. The break point, which has a mean of $380-\mathrm{mm}$ with a range between 440 and $350 \mathrm{~mm}$, is
\end{abstract}


remarkably similar to the 370-mm threshold of the inverse texture hypothesis, below which coarse-texture soils had higher productivity than fine-textured soils. 


\section{Introduction}

Major droughts and floods will become more frequent (Solomon et al. 2007; Field 2012) because of the increase in greenhouse gas concentration, as predicted by models (Singh et al. 2013) and as already observed in several regions around the world (Easterling et al. 2000; Christensen and Christensen 2003; Seneviratne et al. 2006; Lewis et al. 2011; Janssen et al. 2014). There will be larger precipitation events interspersed with longer periods of droughts within a year (Hennessy et al. 1997; Trenberth et al. 2003; Kharin et al. 2007), and there will be sequences of extreme dry years followed by multi-year extremely wet periods (Seneviratne et al. 2006; Lewis et al. 2011). Mechanisms for the increased precipitation variability at the intra- and inter-annual scales are different (Trenberth et al. 2003). At the intra-annual scale, increased precipitation variability results from the warming of the atmosphere and its increased water-holding capacity yielding increases in variability that range from $2.5 \%$ when constrained by the troposphere energy budget (Liu et al. 2013) to 7\% per degree Kelvin as predicted by Clausius-Clapeyron relationship (Trenberth et al. 2003; Kharin et al. 2007). Greenhouse-gas-induced global warming results in increased precipitation variability at the inter-annual scale through other mechanisms, such as intensification of El Niño (Easterling et al. 2000; Lewis et al. 2011) or large-scale rearrangements of atmospheric circulation such as displacement of intertropical convergence (Malhi et al. 2008) or northward shift of climatic zones (Seneviratne et al. 2006).

Effects of changes in precipitation amount and its interactions with other global change drivers have been explored using experiments and models (Luo et al. 2008). Effects of precipitation variability have been studied in plants at short temporal scales (Robinson and Gross 2010; Reyer et al. 2013). However, the effects of increased precipitation variability on the functioning of plants and ecosystems at a continental scale have received much less attention 
than effects of directional changes in temperature, precipitation and $\mathrm{CO}_{2}$ concentration (Field 2012). Consequently, there is not a clear understanding of the differential effects of inter- and intra-annual precipitation variability, or whether increased precipitation variability will have negative or positive effects on ecosystem functioning. The relatively small scientific attention paid to consequences of precipitation variability contrasts with the fact that this topic is now part of the public narrative of climate change. A recent poll reported that 82 percent of Americans report that they personally experienced one type of extreme weather in the last year, and a large majority, ranging from 59 to $72 \%$, believes that global warming made several high profile weather events worse. (Leiserowitz et al. 2012). Our objective was to elucidate the differential effects of intra- and interannual precipitation variability on soil-water availability, the major determinant of functioning in grasslands, a spatially-extensive ecosystem type that covers nearly $41 \%$ of the Earth's land surface and accounts for an important fraction of the global carbon budget (Reynolds et al. 2007; Poulter et al. 2014).

We focused on the dry ecoregion of North America including deserts, steppes, mixed grasslands and temperate prairies (Bailey 1998) (Fig. 1). This 3,200,000 $\mathrm{km}^{2}$ region is an ideal system to address effects of intra- and inter-annual precipitation variability on water availability at the continental scale because it has a strong W-E precipitation gradient (100-900 mm) orthogonal to an N-S temperature gradient $\left(11-24^{\circ} \mathrm{C}\right)$. Precipitation ranges from small amounts and high variability in desert grasslands (mean PPT=240mm, PPT CV=32\%) to sub-humid grasslands receiving large amounts of precipitation and small variability (mean PPT $=835 \mathrm{~mm}$, PPT CV=12\%).

Soil-water availability, as the major determinant of the functioning of ecosystems, limits plant and microbial growth, and results from a balance between inputs and outputs. The major input is precipitation, and major outputs are plant transpiration, bare soil evaporation, and deep 
percolation beyond rooting depth. At the plot scale, run-on and runoff have negligible effects. Plant transpiration depends on: (1) evaporative demand that is determined by air temperature, radiation, humidity, and wind speed, and (2) soil water availability (Jackson et al. 2000). The latter depends on the amount of water, its distribution in the soil profile, and the distribution of active roots in the soil profile (Schulze et al. 1996). A mismatch between the distribution of active roots and soil water in the profile can severely constrain transpiration. Bare soil evaporation occurs mostly from the uppermost soil layers and therefore depends on evaporative demand and water availability in those layers. Finally, when upper layers are saturated and inputs exceed root absorption and soil evaporation, water moves downward beyond the layers explored by roots (deep percolation).

This work aimed at addressing four fundamental questions. (1) How are major paths of ecosystem-water loss (transpiration, soil evaporation, deep percolation) affected by the magnitude of precipitation variability from natural to increased variability up to $75 \%$ ? (2) How are the paths of water loss affected by the scale of precipitation variability from intra- to inter annual and longer? (3) How do the effects of magnitude of variability and its temporal scale on water losses change along regional gradients of mean annual precipitation (MAP)? How do MAP, variability magnitude, and temporal scale affect water available to plants?

We addressed these questions by performing experimental simulations using a processbased model (SOILWAT(Parton 1978)) in which we manipulated the magnitude of precipitation variability (control, enhanced by 25, 50, or 75\%) and its scale (intra- and inter-annual at 1, 3, 6, 9 and 12 year scales) for 35 grassland locations (Fig 1). For example, we enhanced intra-annual variability by $25 \%$ by multiplying each odd precipitation event by 1.25 and even precipitation event by 0.75 such that at the end of each year, the total amount was not modified but the 
variability was enhanced (S1). In other words, in a hypothetical site that has 30 rainfall events per year, events $1,3 \ldots 29$ were multiplied by 1.25 and events $2,4,6 \ldots 30$ by 0.75 . Similarly, to enhance variability at the inter-annual or multi-year scale, we multiplied total precipitation in each year or group of years by multipliers according to target variability magnitudes. Response variables were transpiration, soil evaporation, deep percolation, and soil water availability for 9 different soil layers. For each location and experimental simulation, we ran the model for 100 years of modified precipitation while maintaining temperature at the recorded levels. Four variability magnitudes $* 6$ temporal scales $* 35$ sites $* 12$ response variables $* 365$ days $* 100$ years yielded $3.67 \times 10^{8}$ outputs for analysis.

Our approach was based on the conceptual framework (eq 1) that the impact of climate Eq 1 Impact of climate change $=f($ Climate Change, Ecosystem Sensitivity $)$ change on ecosystem processes is a function of the degree of climate change and the sensitivity of ecosystems. In our case, the impact on ecosystem functioning depends on ecosystem sensitivity to precipitation variability and the degree that precipitation variability will increase, which in turn will vary with time into the future and magnitude of climate change drivers. Our objective was to assess the second part of equation 1, the sensitivity of ecosystems to enhanced precipitation variability. We chose to explore a range of precipitation variability that would encompass changes predicted by global circulation models under various scenarios (Seneviratne et al. 2012). The IPCC special report on extreme events (Seneviratne et al. 2012) predicts for North America a reduction in the 20 -yr precipitation return period, relative to late $20^{\text {th }}$ century for the period 2081-2100, ranging from 10 to 7 years for the B1 and A 2 scenarios. Our experimental simulations reduced the 20 -yr return time of annual precipitation from 18 years up to 3 years (Fig 2). The experimental return period depended on the scale at which we modified 
precipitation variability and the magnitude of the manipulation. Intra-annual variability had a smaller effect than interannual; and the higher the simulated precipitation variability the smaller the return period.

\section{Materials and Methods}

\subsection{Modeling approach}

We used the simulation model SOILWAT (Parton 1978) that has been used extensively in several ecosystems around the world encompassing different vegetation types from deserts and grassland to shrublands and forests (Parton et al. 1987; Parton et al. 1988; Sala et al. 1992; Lauenroth et al. 1993; Lauenroth et al. 1994; Coffin and Lauenroth 1996; Peters 2000 ; Parton et al. 2001a; Parton et al. 2001b; Lauenroth and Bradford 2009; Lauenroth and Bradford 2012; Lauenroth et al. 2014). This model has proven to be a reliable tool to examine relationships among variables and drivers, to integrate experimental results, and to explore ecosystem responses beyond the spatial and temporal domain of the experiments. We used the ecosystem model SOILWAT (Parton 1978) in all 35 locations in our study area (Fig. 1) under both current climate and scenarios of enhanced precipitation variability.

\subsection{Model Description}

SOILWAT is a multi-layer, daily time-step model that simulates soil water content (SWC) by depth in the soil profile (Parton 1978; Peters et al. 2010). Processes simulated in SOILWAT include water interception and subsequent evaporation from the plant canopy and litter, water infiltration into the soil, vertical water flow among soil layers, evaporation and transpiration from each soil layer, and soil water content by layer. SOILWAT does not model run-on and run 
off assuming that they cancel each other and/or that the simulated plots are located on flat terrain. While run off is important to address watershed-scale questions, it is not necessary for the current study that focuses on the plot scale. Evaporation only occurs from the uppermost layers of the soil. SOILWAT requires input information about weather, soil properties and vegetation. Weather inputs include daily precipitation and temperature, and monthly relative humidity, wind speed and cloud cover. Soil properties for each of nine layers $(0-5 \mathrm{~cm}, 5-10 \mathrm{~cm}$, $10-15 \mathrm{~cm}, 15-20 \mathrm{~cm}, 20-30 \mathrm{~cm}, 30-40,40-50,50-80,80-100 \mathrm{~cm})$ consist of texture (\% sand, silt, clay) and \% rocks by volume. Field capacity and wilting point are calculated for each layer based on texture of the soil volume.

\subsection{Experimental Simulations}

First, we run the model SOILWAT for average climate conditions for 100 years. Then, we performed several experiments by generating future climate with increased precipitation variability. We increased intra-annual precipitation variability by 25,50 , and $75 \%$. In order to increase variability by $25 \%$, in a $100-y r$ sequence of precipitation events, we added $25 \%$ to odd events and subtracted $25 \%$ from even events. So at the end, each treatment had the same total precipitation than the control but the variability was enhanced (See Electronic Supplementary material S1). We repeated the same exercise with 50 and $75 \%$ enhanced variance. A second experiment comprised altering variability at the inter-annual scale. In this case, we added $25 \%$ to all the events in odd years and subtracted $25 \%$ to all events in even years in the 100 -year record, so at the end of the 100-year period total precipitation was the same as control but the variability was $25 \%$ higher (S1). We repeated the experiment for 50 and $75 \%$ increased variability. Finally, we enhanced precipitation variability at the 3,6,9 and 12-year scale. For example, in the 3-year 
case, we added $25 \%$ to each event in the first 3 years (years 1-3), subtracted $25 \%$ in the following 3years (years 4-6), and added $25 \%$ for years $7-9$. We followed the same pattern until the end of the 100 year period and increased variability for 6, 9 and 12-year variability treatments following the same procedure. We repeated this exercise for 35 locations that encompass the climatic variability of North American arid to sub-humid ecosystems that range from deserts to temperate grasslands (Fig.1). This region represents most of the climatic variability of global drylands (Bailey 1998).

\subsection{Statistical analyses}

All data analyses were performed in R v. 2.12 (R Development Core Team 2012). We ran ANCOVA analyses for each response variable at each variability temporal scale. Each linear model included one response variable (transpiration, evaporation, percolation or wet-soil days) as a function of one continuous variable (mean annual precipitation) and one categorical variable (variability magnitude treatments: control, $+25 \%,+50 \%$ and $+75 \%$ ) as a covariate. The control treatment was used as a baseline to which we contrasted all other levels of increased precipitation variability. Interaction terms between each increased precipitation variability and mean annual precipitation were included in all cases but dropped when they were not significant. In order to test the significance of the break point we also ran separate analyses for sites where MAP falls below (Site MAP $<38 \mathrm{~cm}$ ) around $(28 \mathrm{~cm}<$ Site MAP $<48 \mathrm{~cm}$ ) and above (Site MAP > 38) the break point. We used 5\% significance level for single test analyses and adjusted our alpha value in order to maintain a 5\% family wise significance level on multi-test analyses using the Bonferroni adjusted p-value (Wright 1992). Supplementary tables present analyses on transpiration and evaporation (S2a) and percolation and wet-soil days (S2b). 


\subsection{Model parameterization}

We collected daily precipitation and temperature, and monthly relative humidity, wind speed and cloud cover data for the 35 locations (Fig.1) from US National Climate Data Center (NCDC; (http://www.ncdc.noaa.gov/oa/ncdc.html). Then, we used these data in a first-order Markov analysis to generate 100 years of daily climate variables for each site (Minnick and Coffin 1999; Peters 2000). A Markov analysis retains the pattern of rainfall amount observed in the historic data. To avoid confounding continental climate and soil patterns, the model used a single soil profile representing a sandy-loam soil (58\% sand, $19 \%$ clay). Given that our questions were about precipitation variability, we kept soil characteristics constant. We repeated the same analysis with clay-loam soils (32\% sand, $34 \%$ clay) and found the same patterns. Consequently, clay-loam results are not reported here. We used SOILWAT to model the effect of precipitation variability on several ecosystem-level variables across a broad range of climatic conditions. Although those conditions coincide with different vegetation types from a biogeographical point of view (Bailey 1998), SOILWAT was not parameterized differently for each vegetation type assuming that ecosystem characteristics do not change independently of climate but they are determined by climate.

\subsection{Response variables}

Runs of SOILWAT for 100 years and experiments generated a large volume of data. In order to address the central questions of this work, we report on a synthetic variable of soil water availability and the three major losses of water from the soil: plant transpiration, soil evaporation, and deep percolation. Because it was difficult to report soil water content for every 
single layer, day and experimental condition, we chose to use the number days in which the soil water potential was above $-1 \mathrm{MPa}$. Changing this threshold to define wet conditions to $-1.5 \mathrm{MPa}$ did not modify any of the results and conclusions.

\section{Results}

Transpiration increased with mean annual precipitation (MAP) from arid to semiarid and subhumid ecosystems (Fig. 3 a-c and S2 a-c). The magnitude of precipitation variability had different effects on transpiration depending on the scale of variability and the MAP of the site. At the intra-annual scale, we found no effect of increased precipitation variability on transpiration. However, at the inter-annual scales, enhanced variability resulted in an increase in transpiration for sites with low MAP and reduced transpiration for sites with high MAP. The MAP value at which the enhanced variability model crossed the control, or the MAP at which there was no effect between control and enhanced precipitation variability, ranged between 440 and $350 \mathrm{~mm} \mathrm{yr}^{-1}$ for the different treatments with a mean of $380 \mathrm{~mm} \mathrm{yr}^{-1}$.

A detailed statistical analysis that divided the precipitation gradient in three segments, $<380,280-480,>380 \mathrm{~mm} \mathrm{yr}^{-1}$, reinforced the pattern reported above regarding the effects on transpiration of magnitude of precipitation variability and the scale of variability, from intra-

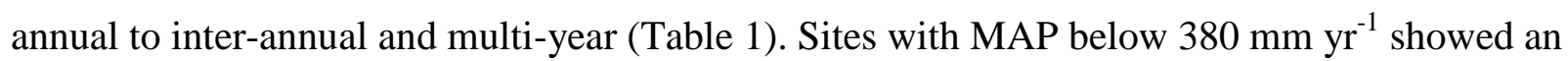
increase in transpiration with increasing precipitation variability; sites receiving between 280 and $480 \mathrm{~mm}$ of annual precipitation showed no effect of variability, and sites above $380 \mathrm{~mm} \mathrm{yr}^{-1}$ showed a negative effect of precipitation variability. Another important aspect of this analysis is that the effect of the scale of variability is larger than the effect of the magnitude of variability. At the intra-annual scale, there was a significant effect only at $75 \%$ enhanced precipitation 
variability in the $<380 \mathrm{~mm} \mathrm{yr}^{-1}$ group. In the case of the six-year inter-annual scale of variability, there were significant differences in both regions below and above $380 \mathrm{~mm} \mathrm{yr}^{-1}$, and for 50 and $75 \%$ enhanced precipitation variability.

Soil evaporation decreased with MAP as a result of increasing leaf area and a corresponding reduction in bare soil (Fig. 3 d-f and S2 d-f). In arid sites with low plant cover and a high percentage of bare soil, a larger fraction of the water losses occur via soil evaporation. Variability at the 3- and 6-yr scales decreased soil evaporation for all locations regardless of MAP (Table 1). Deep percolation increased with MAP, and precipitation variability enhanced this effect (Table 1, Fig. 3 g-i and S2 g-i). Patterns in soil water availability, expressed as the average number of days per year when the soil was wet (soil water potential > $-1 \mathrm{MPa}$ ), reflected patterns of transpiration, evaporation and deep percolation (Fig $3 \mathrm{j}-\mathrm{i}$ and $\mathrm{S} 2 \mathrm{j}-\mathrm{i}$ ). Increased precipitation variability increased soil water availability in sites with mean annual precipitation less than $380 \mathrm{~mm} \mathrm{yr}^{-1}$ and strongly decreased it in sites with mean annual precipitation greater than $380 \mathrm{~mm} \mathrm{yr}^{-1}$ response (Table 1).

The effects of precipitation variability on water losses were associated with changes in the distribution of available water in the soil profile (Fig 4. a-b). In locations with MAP below the $380 \mathrm{~mm} \mathrm{yr}^{-1}$, increased precipitation variability resulted in a deepening of the soil water profile (Fig 4. a). There was a significant $(\mathrm{P}<0.05)$ increase in the number of wet days in deeper soil layers as a result of increased precipitation variability. Maximum soil wetness, expressed as number of wet days per year, occurred at $10-\mathrm{cm}$ depth in the control and at $50-\mathrm{cm}$ depth in the $75 \%$ enhanced precipitation variability treatment. In the uppermost soil layers, there were no changes in the number of wet days, which remained very low and close to the number of events per year. In these dry environments, the top layer only stays wet the day that it rains and the day 
after, independently of event size. In locations above $380 \mathrm{~mm} \mathrm{yr}^{-1}$, increased precipitation variability significantly decreased water availability in the uppermost layer while deepest layer remained wet (Fig 4. b).

\section{Discussion}

The first conclusion of this article is that the scale of variability had a much larger effect on transpiration, percolation and soil water availability than the magnitude of variability. At the intra-annual scale, increased variability from control up to $+75 \%$ had non-significant effects on soil-water availability and all paths of water loss. On the contrary, the same increased variability had a much larger effect at the 3 or 6-yr time scale. Consequently, the effects of climate change on multi-year increased variability will have a larger ecosystem impact than its effects on intra-

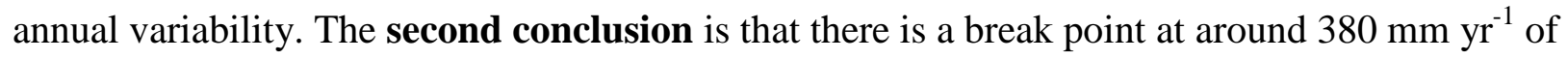
MAP, ranging between 440 and $350 \mathrm{~mm} \mathrm{yr}^{-1}$. Below $380 \mathrm{~mm} \mathrm{yr}^{-1}$, enhanced precipitation variability increased soil-water and plant transpiration whereas above $380 \mathrm{~mm} \mathrm{yr}^{-1}$, increased precipitation variability decreased soil-water availability and transpiration, mostly through enhanced deep percolation.

The mechanism of the effects of precipitation variability on water availability with differential effects on arid and mesic grasslands is related to its effects on water distribution in the soil profile (Fig 4. a-b). In ecosystems with MAP below $380 \mathrm{~mm} \mathrm{yr}^{-1}$, enhanced variability at 3 and 6-years shifted the soil-water profile downwards (Fig. 4a). Consequently, there was a reduction in bare soil evaporation, which occurs only from the uppermost layer, and an increase in transpiration. Because the total amount of precipitation is low, enhanced precipitation variability did not affect deep percolation, which in all cases was negligible. In grasslands with 
MAP above $380 \mathrm{~mm} \mathrm{yr}^{-1}$, enhanced precipitation variability also shifted the soil-water availability profile downwards with a reduction in soil water in the uppermost layers. This change in the distribution of soil water towards deeper soil layers significantly increased deep percolation and had small effect on soil evaporation, which is already very small in humid ecosystems with high plant cover and minimum bare soil. The increased in deep percolation and the negligible effect on evaporation resulted in a reduction in water availability and transpiration (Fig, 4b). Increased precipitation variability drastically increased deep percolation and reduced the amount of water in the soil profile explored by roots. Increased precipitation variability also reduced soil evaporation, but this loss is quite small in mesic ecosystems and therefore had minimal impact on overall water balance.

The mechanism linking increased precipitation variability with the shift in the location of the water-availability profile is the result of the disproportional increase of depth of water penetration with amount of rainfall (Sala et al. 1992). The increasing depth per unit of rainfall with increasing annual rainfall results from the decreasing importance of the upward flow of soil evaporation (Fig 3). For example, evaporation is approximately $50 \%$ of total rainfall in sites with $300 \mathrm{~mm} \mathrm{yr}^{-1}$ of mean annual precipitation, and $20 \%$ in sites with $600 \mathrm{~mm} \mathrm{yr}^{-1}$ (Fig 3). Under wet conditions, each rainfall event has a high probability of finding a wet soil and penetrating deep into the soil. Under dry conditions, each rainfall event will likely find a dry soil wetting only shallow layers where water is lost via evaporation. In our case, increase in precipitation variability increases the mean depth of the wettest soil layer and deepens the soilwater profile.

The increasing effect of precipitation variability with temporal scale is associated with the amount of precipitation received in a few wet days versus a few wet years. The latter is much 
larger and therefore it results in a further shift in the soil-water profile. A few wet years have a larger impact on the distribution of the water in the soil profile than of a few wet days.

The $380 \mathrm{~mm} \mathrm{yr}^{-1}$ MAP average break point reported here is remarkably similar to the 370

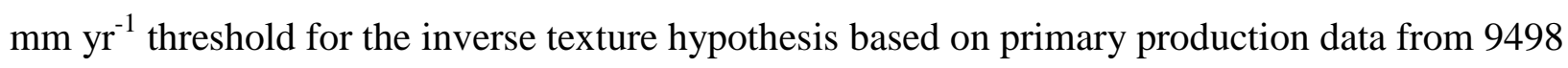
locations in the Central Grassland Region of the US (Sala et al. 1988). The primary production analysis showed that for locations below $370 \mathrm{~mm} \mathrm{yr}^{-1}$, coarse-textured soils (sandy) had higher production than fine-textured soils (clay and silt). On the contrary, sandy soils were less productive than fine textured soils for locations above $370 \mathrm{~mm} \mathrm{yr}^{-1}$. The explanation for the inverse texture hypothesis is also associated with water distribution in the soil profile as modified by soil texture. Sandy soils have low water holding capacity such that the same size precipitation event penetrates deeper than in clay soils. The deeper distribution of water in sandy soils is beneficial in dry ecosystems because it reduces soil evaporation losses and leaves more water available for transpiration. In sites with MAP higher than $370 \mathrm{~mm} \mathrm{yr}^{-1}$, sandy soils are less productive than clay soils because downward water movement in the profile enhances deep percolation with less water available for plants. Both effects are parallel to those generated by increasing precipitation variability. The remarkable match between these two independent analyses, one based on observations of primary production and soils, and the other on modeling, support each other. The modeling experiments support the mechanisms invoked for the inverse texture hypothesis, and the observational data provide an independent validation of the modeling results about effects of precipitation variability on ecosystem water availability.

Our results suggest that climate change-induced increases in precipitation variability will have: (1) beneficial effects on arid ecosystems and negative effects on more mesic ecosystems and (2) larger effects at inter- than intra-annual scale. Pioneering work on ecosystem responses 


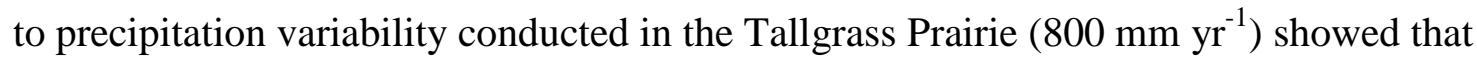
increased intra-annual variability in precipitation can reduce primary production (Heisler-White et al. 2009). Similar experiments in other locations show that increases in intra-annual precipitation variability can increase production in arid ecosystems and decrease it in more mesic ecosystems (Heisler-White et al. 2008; Knapp et al. 2008a; Heisler-White et al. 2009; Thomey et al. 2011). These results at the intra-annual scale support the findings of our modeling experiments. However, we are not aware of experimental manipulations of precipitation variability at the inter-annual scale across a range of grassland types. We speculate that plant community dynamics, which were not included in our modeling effort, will become more important at the inter-annual scale. Death of individuals or plant parts during prolonged drought (Reichmann et al. 2013; Reichmann and Sala 2014) may constrain the ability of arid ecosystems from benefiting from increased water availability associated with higher precipitation variability. Our simulation model yields results that are compatible with the Knapp conceptual model (2008b) although both are different. Knapp's model is based on plant physiology concepts, while ours is based on first principles of soil physics. The Knapp model assumes that there are anoxia and drought thresholds and that plants in xeric systems under ambient conditions are mostly below the drought threshold and increasing precipitation variability puts them above this threshold. In hydric systems and under ambient conditions, plants are between the anoxia and drought thresholds and increasing precipitation variability puts them above the anoxia threshold.

Another consequence of climate-change-induced increased precipitation variability and the resulting downward shift in the soil water profile is that it may lead to changes in plantspecies composition favoring deep rooted over shallow rooted species. These circumstances may accelerate the process of woody-plant encroachment (Barger et al. 2011) where shallow-rooted 
grasses are being replaced by deep-rooted woody plants. This phenomenon is already prevalent with woody-cover increasing at a rate of ranging from 0.5 to $2 \%$ per year and costing large sums of money in several control practices, such as burning or herbicide spraying (Archer and Predick 2014; Ratajczak et al. 2014). Just in the US and between 2005 and 2009, the Natural Resource Conservation Service has spent \$127M in brush control (Tanaka et al. 2011). A recent study reported that woody-plant encroachment in North and South America results in significant decreases in livestock production, which is one of the major ecosystem services of drylands (Anadón et al. 2014). Regardless of the current origin of this phenomenon, our results suggest that it will be accelerated as a result of the expected increase in precipitation variability.

\section{Acknowledgements}

The authors thank Haitao Huang for model simulations, reviewers and editor for positive suggestions that significantly improved the manuscript and finally G.A. Gil and D. Correa for assistance and guidance. This research was financially supported by NSF DEB 09-17668 and DEB 12-35828. 


\section{References}

Anadón JD, Sala OE, Turner BL, Bennett EM (2014) The effect of woody-plant encroachment on livestock production in North and South America Proceedings of National Academy of Sciences 111:12948-12953 doi:www.pnas.org/cgi/doi/10.1073/pnas.1320585111

Archer SR, Predick KI (2014) An ecosystem services perspective on brush management: research priorities for competing land-use objectives Journal of Ecology 102:1394-1407 doi:10.1111/1365-2745.12314

Bailey RG (1998) Ecoregions: the ecosystem geography of the oceans and continents. Springer, New York

Barger NN, Archer SR, Campbell JL, Huang Cy, Morton JA, Knapp AK (2011) Woody plant proliferation in North American drylands: a synthesis of impacts on ecosystem carbon balance Journal of Geophysical Research 116

Christensen JH, Christensen OB (2003) Climate modelling: Severe summertime flooding in Europe Nature 421:805-806 doi:10.1038/421805a

Coffin D, Lauenroth W (1996) Transient responses of North-American grasslands to changes in climate Climatic Change 34:269-278 doi:10.1007/bf00224638

Easterling DR, Meehl GA, Parmesan C, Changnon SA, Karl TR, Mearns LO (2000) Climate extremes: Observations, modeling, and impacts Science 289:2068-2074

Field CB (2012) Managing the risks of extreme events and disasters to advance climate change adaptation: Special report of the intergovernmental panel on climate change. Cambridge University Press,

Heisler-White JL, Blair JM, Kelly EF, Harmoney K, Knapp AK (2009) Contingent productivity responses to more extreme rainfall regimes across a grassland biome Glob Change Biol 15:2894-2904 doi:10.1111/j.1365-2486.2009.01961.x

Heisler-White JL, Knapp AK, Kelly EF (2008) Increasing precipitation event size increases aboveground net primary productivity in a semi-arid grassland Oecologia 158:129-140 doi:10.1007/s00442-008-1116-9

Hennessy KJ, Gregory JM, Mitchell JFB (1997) Changes in daily precipitation under enhanced greenhouse conditions Climate Dynamics 13:667-680 doi:10.1007/s003820050189

Jackson RB, Sperry JS, Dawson TE (2000) Root water uptake and transport: using phisiological processes in global predictions Trends in plant science 5:482-488 
Janssen E, Wuebbles DJ, Kunkel KE, Olsen SC, Goodman A (2014) Observational-and modelbased trends and projections of extreme precipitation over the contiguous United States Earth's Future 2:99-113

Kharin VV, Zwiers FW, Zhang XB, Hegerl GC (2007) Changes in temperature and precipitation extremes in the IPCC ensemble of global coupled model simulations J Clim 20:14191444 doi:10.1175/jcli4066.1

Knapp AK et al. (2008a) Consequences of more extreme precipitation regimes for terrestrial ecosystems Bioscience 58:811-821 doi:10.1641/b580908

Knapp AK et al. (2008b) Shrub encroachment in North American grasslands: shifts in growth form dominance rapidly alters control of ecosystem carbon inputs Glob Change Biol $14: 615-623$

Lauenroth WK, Bradford JB (2009) Ecohydrology of dry regions of the United States: precipitation pulses and intraseasonal drought Ecohydrology 2:173-181 doi:10.1002/eco.53

Lauenroth WK, Bradford JB (2012) Ecohydrology of dry regions of the United States: water balance consequences of small precipitation events Ecohydrology 5:46-53 doi:10.1002/eco.195

Lauenroth WK, Sala OE, Coffin CP, Kirchner TB (1994) The importance of soil water in the recruitment of Bouteloua gracilis in the shortgrass steppe Ecological Applications 4:741749

Lauenroth WK, Schlaepfer DR, Bradford JB (2014) Ecohydrology of Dry Regions: Storage versus Pulse Soil Water Dynamics Ecosystems 17:1469-1479 doi:10.1007/s10021-0149808-y

Lauenroth WK, Urban DL, Coffin DP, Parton WJ, Shugart HH, Kirchner TB, Smith TM (1993) Modeling vegetation structure-ecosystem process interactions across sites and ecosystems Ecological Modelling 67:49-80 doi:http://dx.doi.org/10.1016/0304-3800(93)90099-E

Leiserowitz A, Maibach E, Roser-Renouf C, Hmielowski JD (2012) Extreme Weather,Climate \& Preparedness in the American Mind. New Haven, CT

Lewis SL, Brando PM, Phillips OL, van der Heijden GMF, Nepstad D (2011) The 2010 Amazon Drought Science 331:554-554 doi:10.1126/science.1200807 
Liu J, Wang B, Cane MA, Yim S-Y, Lee J-Y (2013) Divergent global precipitation changes induced by natural versus anthropogenic forcing Nature 493:656-659

Luo Y et al. (2008) Modeled interactive effects of precipitation, temperature, and [CO2] on ecosystem carbon and water dynamics in different climatic zones Glob Change Biol 14:1986-1999 doi:10.1111/j.1365-2486.2008.01629.x

Malhi Y, Roberts JT, Betts RA, Killeen TJ, Li WH, Nobre CA (2008) Climate change, deforestation, and the fate of the Amazon Science 319:169-172 doi:10.1126/science.1146961

Minnick TJ, Coffin DP (1999) Geographic patterns of simulated establishment of two Bouteloua species: implications for distributions of dominants and ecotones J Veg Sci 10:343-356

Parton W et al. (2001a) Generalized model for $\mathrm{NO}_{\mathrm{x}}$ and $\mathrm{N}_{2} \mathrm{O}$ emissions from soils Journal of Geophysical Research 106:17403-17419

Parton W, Schimel DS, Cole C, Ojima D (1987) Analysis of factors controlling soil organic matter levels in Great Plains grasslands Soil Science Society of America Journal $51: 1173-1179$

Parton WJ (1978) Abiotic section of ELM. In: Innis GS (ed) Grassland simulation model, vol Ecological Studies Vol. 26. Springer-Verlag, New York, pp 31-53

Parton WJ, Morgan JA, Kelly RH, Ojima DS (2001b) Modeling soil C responses to environmental change in grassland ecosystems. CRC Press, Boca Raton, FL.

Parton WJ, Stewart JW, Cole CV (1988) Dynamics of C, N, P and S in grassland soils: a model Biogeochemistry 5:109-131

Peters D (2000) Climatic variation and simulated patterns in seedling establishment of two dominant grasses at a semiarid-arid grassland ecotone J Veg Sci 11:493-504

Peters DPC, Herrick JE, Monger HC, Huang HT (2010) Soil-vegetation-climate interactions in arid landscapes: Effects of the North American monsoon on grass recruitment Journal of Arid Environments 74:618-623 doi:10.1016/j.jaridenv.2009.09.015

Poulter B et al. (2014) Contribution of semi-arid ecosystems to interannual variability of the global carbon cycle Nature advance online publication doi:10.1038/nature13376

R Development Core Team (2012) R: a language and environment for statistical computing, Version: 2.14.2 edn. edn. R Foundation for Statistical Computing, Vienna, Austria 
Ratajczak Z, Nippert JB, Briggs JM, Blair JM (2014) Fire dynamics distinguish grasslands, shrublands and woodlands as alternative attractors in the Central Great Plains of North America Journal of Ecology 102:1374-1385 doi:10.1111/1365-2745.12311

Reichmann LG, Sala OE (2014) Differential sensitivities of grassland structural components to changes in precipitation mediate productivity response in a desert ecosystem Functional Ecology 28:1292-1298 doi:DOI: 10.1111/1365-2435.12265

Reichmann LG, Sala OE, Peters DPC (2013) Precipitation legacies in desert-grassland primary production occur through previous-year tiller density Ecology 94:435-443 doi:http://dx.doi.org/10.1890/12-1237.1

Reyer CP et al. (2013) A plant's perspective of extremes: terrestrial plant responses to changing climatic variability Global change biology 19:75-89

Reynolds JF et al. (2007) Global desertification: building a science for dryland development Science 316:847-851

Robinson TM, Gross KL (2010) The impact of altered precipitation variability on annual weed species American journal of botany 97:1625-1629

Sala OE, Lauenroth WK, Parton WJ (1992) Long term soil water dynamics in the shortgrass steppe Ecology 73:1175-1181

Sala OE, Parton WJ, Lauenroth WK, Joyce LA (1988) Primary production of the central grassland region of the United States Ecology 69:40-45 doi:10.2307/1943158

Schulze ED et al. (1996) Rooting depth, water availability, and vegetation cover along an aridity gradient in Patagonia Oecologia 108:503-511

Seneviratne SI, Luthi D, Litschi M, Schar C (2006) Land-atmosphere coupling and climate change in Europe Nature 443:205-209 doi:10.1038/nature05095

Seneviratne SI et al. (2012) Changes in climate extremes and their impacts on the natural physical environment Managing the risks of extreme events and disasters to advance climate change adaptation:109-230

Singh D, Tsiang M, Rajaratnam B, Diffenbaugh NS (2013) Precipitation extremes over the continental United States in a transient, high-resolution, ensemble climate model experiment Journal of Geophysical Research: Atmospheres 118:7063-7086

Solomon S et al. (eds) (2007) Climate Change 2007: The Physical Science Basis. Cambridge University Press, Cambridge 
Tanaka JA, Brunson M, Torell LA (2011) A social and economic assessment of rangeland conservation practices. In: Briske DD (ed) Conservation benefits of rangeland practices: assessment, recommendations, and knowledge gaps. Natural Resources Conservation Service, Washington, DC: USDA, pp 371-422

Thomey ML, Collins SL, Vargas R, Johnson JE, Brown RF, Natvig DO, Friggens MT (2011) Effect of precipitation variability on net primary production and soil respiration in a Chihuahuan Desert grassland Glob Change Biol 17:1505-1515 doi:10.1111/j.13652486.2010.02363.x

Trenberth KE, Dai A, Rasmussen RM, Parsons DB (2003) The changing character of precipitation Bulletin of the American Meteorological Society 84:1205-1218 Wright SP (1992) Adjusted p-values for simultaneous inference Biometrics:1005-1013 
Table 1 Estimates of slopes of linear regression models of ANCOVA coefficients for transpiration as function of mean annual precipitation for three levels of precipitation variability (control, $+25 \%,+50 \%,+75 \%$ ) for and two temporal scales of precipitation variability (Intra-annual and six-year interannual). The same analysis was repeated for sites below $38 \mathrm{~cm}$, between $28 \mathrm{~cm}$ and $48 \mathrm{~cm}$, and over $38 \mathrm{~cm}$ mean annual precipitation. Estimates are the

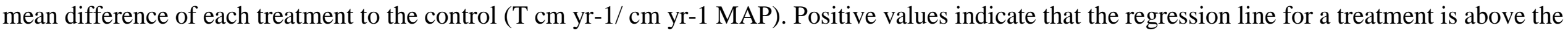
control and negative values indicate the opposite. Asterisks indicate significant differences at 5\% and period indicate significant difference at $10 \%$ familywise level of significance.

Site $M A P<38 \mathrm{~cm}$

\section{Transpiration}

Evaporation

Percolation

Wet-soil days

Variability

Variability Scale

Magnitude

Intra- 6-year Inter-

annual annual

Variability Scale

Intra-annual

6-year Inter0.45 ns $\quad-0.18$ ns

$\begin{array}{lll}25 \% & 0.21 & \text { ns } \\ 50 \% & 0.86 & \text { ns } \\ 75 \% & 1.85 & \end{array}$

1.32 .

-0.8 ns

2.45

$-1.68$

Variability Scale

Intra- 6-year Inter-

annual

-0.31 ns $\quad 0.01$ ns

$-1.27 \cdot 0.05^{\mathrm{ns}}$

$-2.76^{*} 0.14^{\mathrm{ns}}$ annual

$\begin{array}{rlrl}0.09 & \text { ns } & 2.08 & \text { ns } \\ 0.44 & \text { ns } & 7.98 & \text { ns } \\ 1.19 & * & 16.98 & *\end{array}$

Variability Scale

6-year Interannual

$2.5^{\mathrm{ns}}$

$7.83^{\mathrm{ns}}$

14.28

$28<$ Site $M A P<48 \mathrm{~cm}$

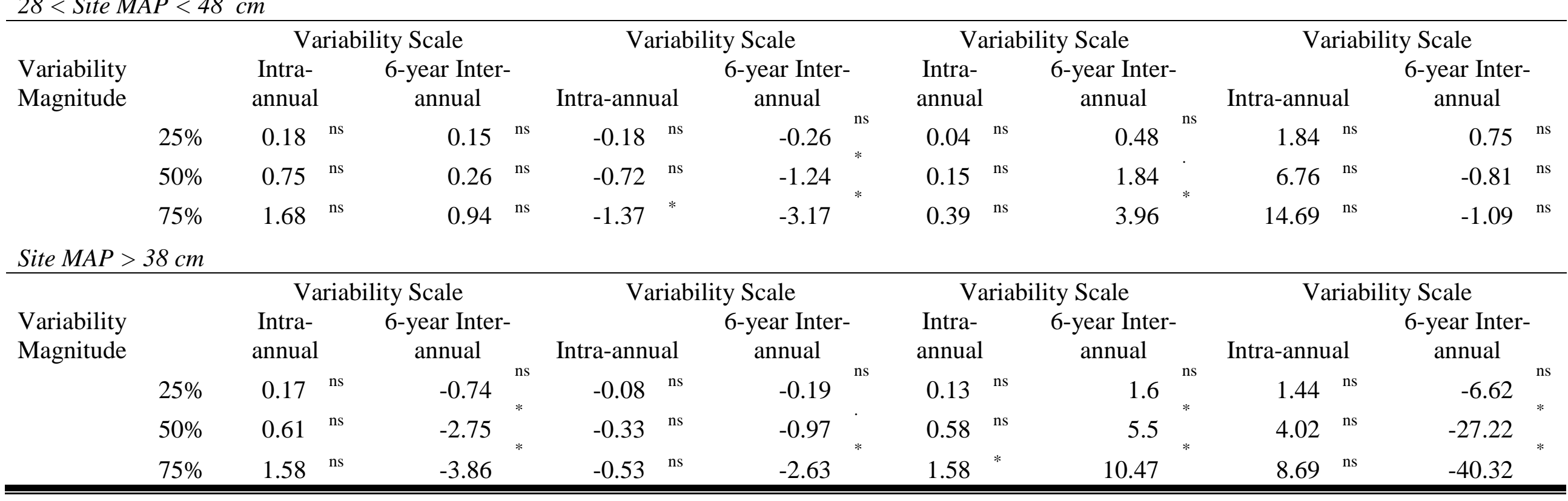




\section{Figure Legends}

Figure 1 Location of the sites where the simulation model was run on a background map of mean annual precipitation. Site code, name and state are SPOK Spokane, WA; BOI Boise, ID; WINN Winnemucca, NV; LVG Las Vegas, NV; SGM Granite Mountains, CA; DCD Deep Canyon Desert, CA; KING Kingman, AZ, CAP Central Arizona Phoenix LTER, AZ; SRE Santa Rita Experimental Range, AZ; WGE Walnut Gulch Experimental Range, AZ; SRS Southwest Research Station, CA; JRN Jornada Basin LTER NM; SEV Sevilleta LTER, NM; NWK; CPER Central Plains Experimental Range LTER, CO; CAS Casper, WY; BILL Billings, MO; FTK Fort Keogh, MO; SHIELDS Shields, ND; BTN Britton, SD; MINN; CDR Cedar Creek LTER, MN; OMAH Omaha, NE; GOOD Goodland, KS; HAYS Hays Experimental Range, KS; GUY Guymon, OK; SPR Southern Plains Range Research Station, OK; GRL Grazinglands Research Laboratory, OK; MID Midland, TX; ROBLEE Robert Lee, TX; GSW Grassland Soil and Water Research Laboratory, TX; BBNP Big Bend National Park, TX.

Figure 2 Return period (in years) of extreme events for all modeled climate treatments Extreme wet (a) and dry (b) events are defined as precipitation years wetter than the $95^{\text {th }}$ and drier than the $5^{\text {th }}$ percentile of the ambient precipitation normal distribution. Dashes indicate the mean return period for the 100-year modeled climate for each treatment. 
Figure 3 Effects of precipitation variability and its scale on plant transpiration, soil evaporation, deep percolation and soil water availability for 35 locations along a gradient of mean annual precipitation. a-c plant transpiration $\left(\mathrm{cm} \mathrm{yr}^{-1}\right)$, d-f soil evaporation $\left(\mathrm{cm} \mathrm{yr}^{-1}\right), \mathbf{g}$ -

$\mathbf{i}$ deep percolation $\left(\mathrm{cm} \mathrm{yr}^{-1}\right)$ and $\mathbf{j}-\mathbf{l}$ soil water availability (number of days per year when average soil water potential was greater than -1 MPa). ). a,d,g,j jhow results of changes in intra-annual

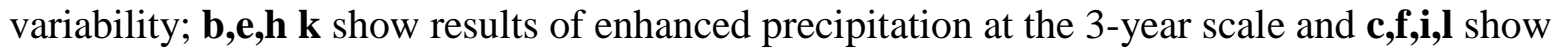
results at the 6-year scale. Each data point represents one of the 35 locations for each treatment and lines are regression lines per treatment. Control (black dots and lines), enhanced precipitation variability by $25 \%$ (green), $50 \%$ (blue) and $75 \%$ (red). Slope of each model is indicated as $\mathrm{b}$ and $\mathrm{R}$ squared values correspond to overall ANCOVA R squared for each variable at each variability scale. Different letters associated with the slopes indicate significant $(\mathrm{p}<0.05)$ differences versus control. Details of statistical analyses can be found in S2a and S2b.

Figure 4 Effects of precipitation variability on the distribution of water in the soil profile as modulated by mean annual precipitation. a for all sites with mean annual precipitation below $380 \mathrm{~mm} \mathrm{yr}^{-1}$ and $\mathbf{b}$ for sites with mean annual precipitation above $380 \mathrm{~mm} \mathrm{yr}^{-1}$. Soil water availability is expressed as the average number of days when soil water potential was above 1MPa. Control (black line), enhanced precipitation variability at the 9 -yr scale by $25 \%$ (green), $50 \%$ (blue) and 75\% (red). Comparisons among variability treatments for each depth are depicted by letters. Each letter indicates the significance difference of each treatment represented by the color at each depth. ns indicates non-significant differences at the indicated depth. 
Fig 1

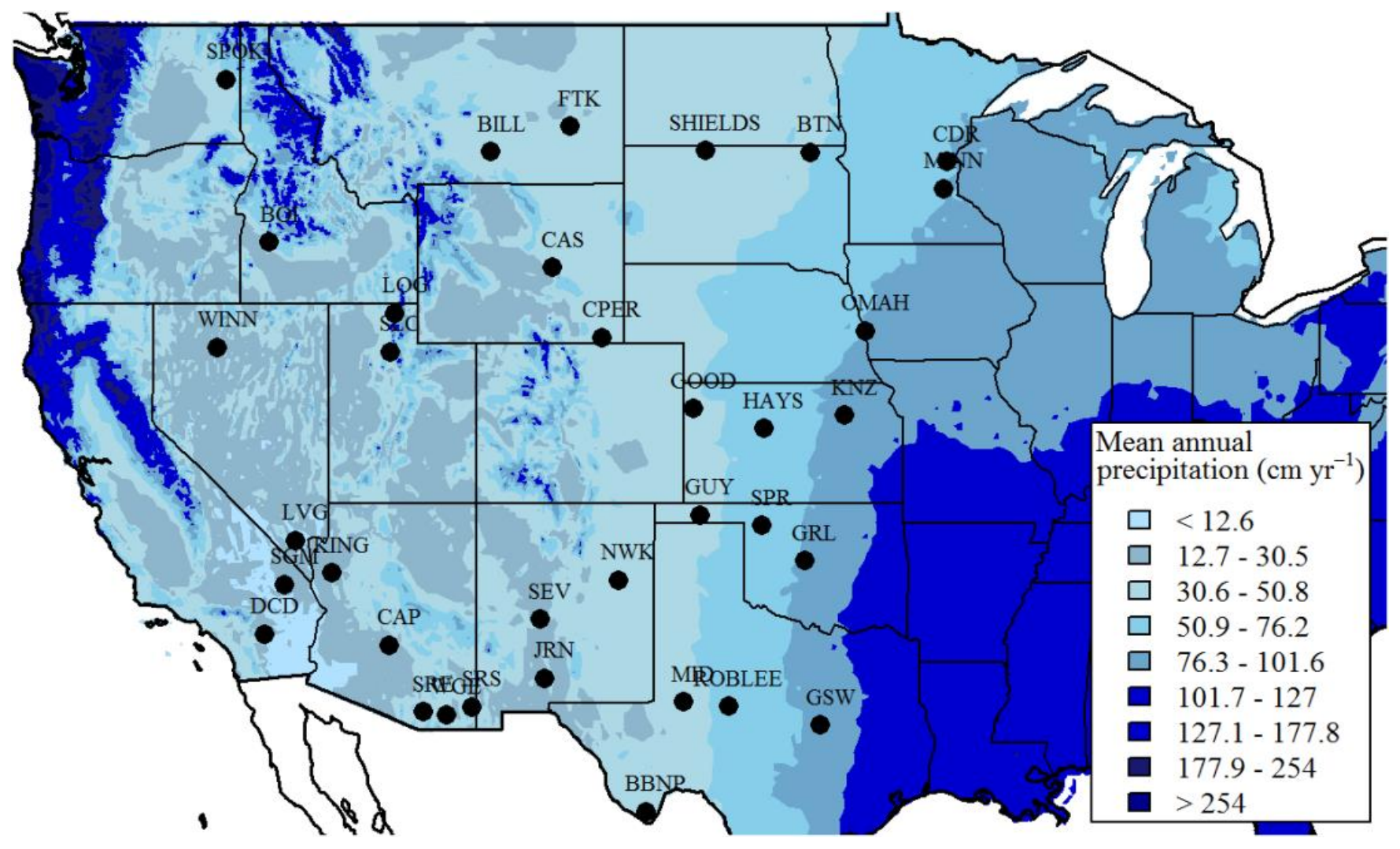


Fig 2

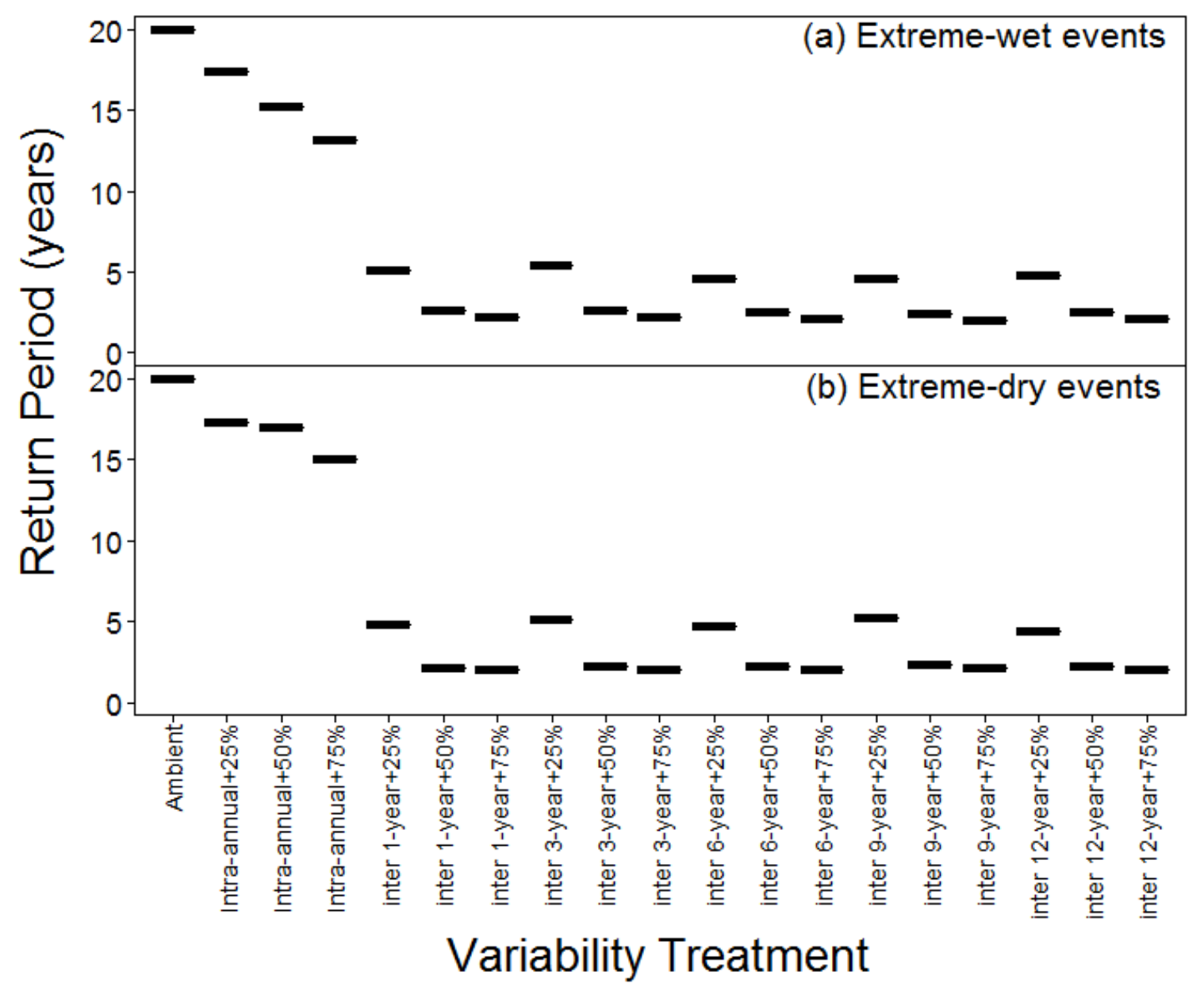


Fig 3

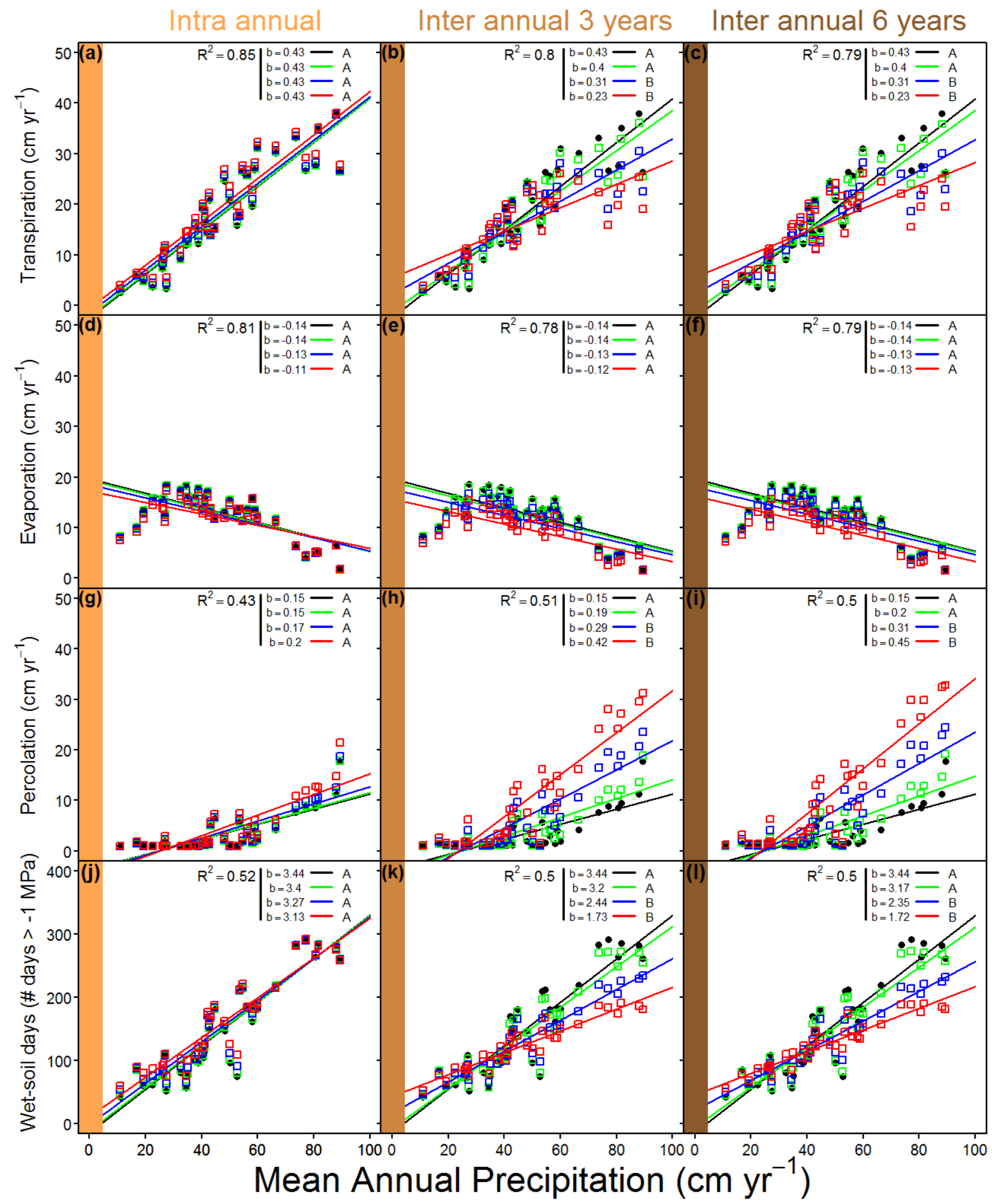


Fig 4

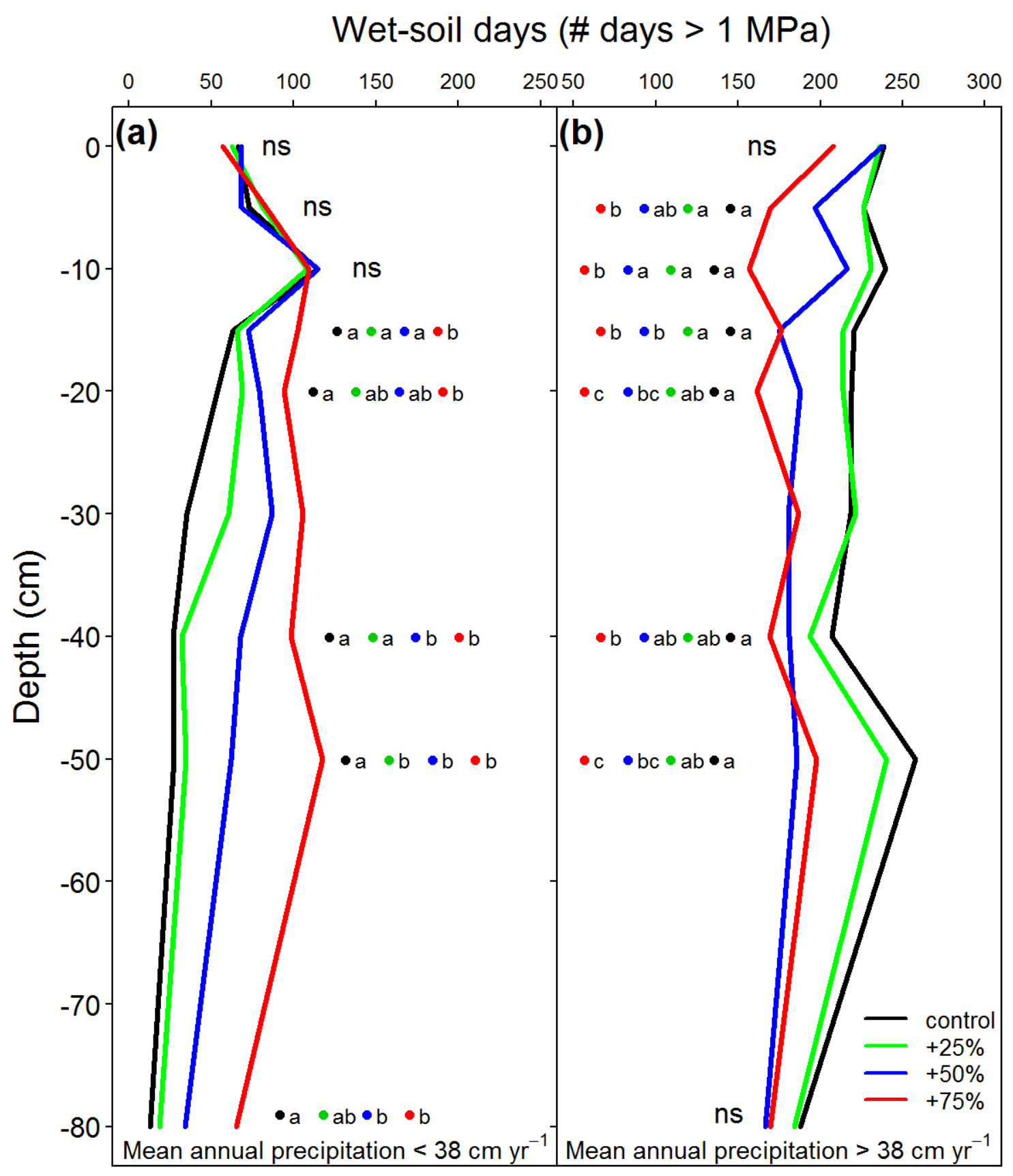




\section{Electronic Supplementary Material}

Enhanced Precipitation Variability Effects on Water Losses and Ecosystem Functioning: Differential Response of Arid and Mesic Regions

Osvaldo E. Sala ${ }^{1,2,3,}$, Laureano A. Gherardi ${ }^{1,3}$, Debra P.C. Peters ${ }^{3,4}$

${ }^{1}$ School of Life Sciences, Arizona State University, Tempe, AZ, 85287-4501, USA

${ }^{2}$ School of Sustainability, Arizona State University, Tempe, AZ, 85287-4501, USA

${ }^{3}$ Jornada Basin Long Term Ecological Research Program, New Mexico State University, Las Cruces, NM, 88003, USA

${ }^{4}$ USDA-ARS, Jornada Experimental Range, Las Cruces, NM 88003, USA

* Corresponding author: Osvaldo Sala, Ph 480-965-4120, Fax 480-727-7584 Email address Osvaldo.Sala@ASU.edu 
S1 Relationship between annual ambient precipitation and the precipitation for all the sites and all the treatments for the experimental 100-year period. Most of the points fall on or close to the 1:1 line indicating that the experimental modification of variability did not modify the mean.

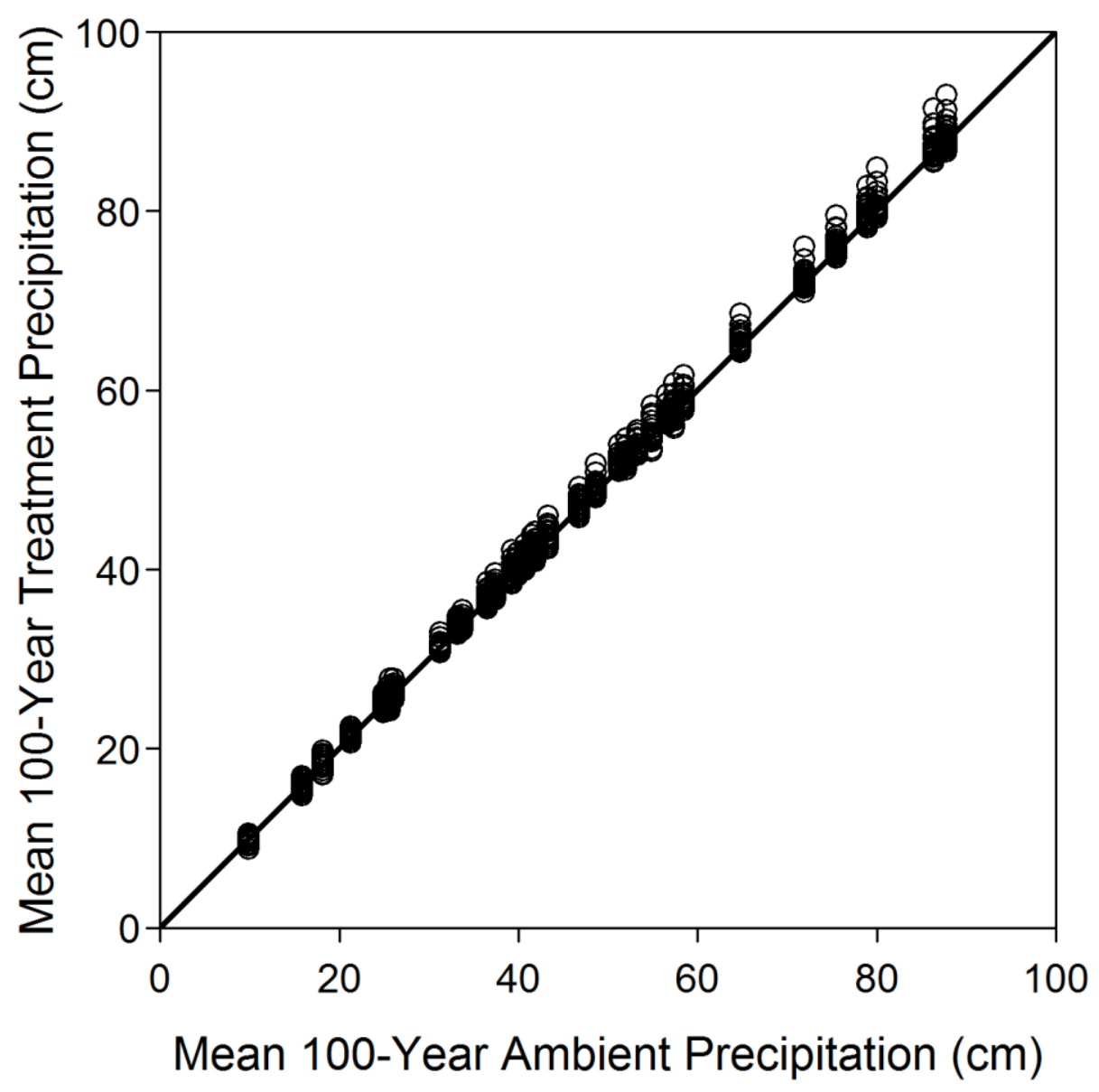


S2 Effects of precipitation variability and its scale on plant transpiration, soil evaporation, deep percolation and soil water availability for 35 locations along a gradient of mean annual precipitation. a-c plant transpiration $\left(\mathrm{cm} \mathrm{yr}^{-1}\right)$, d-f soil evaporation $\left(\mathrm{cm} \mathrm{yr}^{-1}\right)$, g-i deep percolation $\left(\mathrm{cm} \mathrm{yr}^{-1}\right)$ and $\mathbf{j}-\mathbf{l}$ soil water availability (number of days per year when average soil water potential was greater than -1 MPa). a,d,g,j show results of changes in inter-annual variability enhanced precipitation at the 1-year scale; $\mathbf{b}, \mathbf{e}, \mathbf{h} \mathbf{k}$ show results of enhanced precipitation at the 9-year scale and c,f,i,l, show results at the 12-year scale. Each data point represents one of the 35 locations for each treatment and lines regression lines per treatment. Control (black dots and line), enhanced precipitation variability by $25 \%$ (green), 50\% (blue) and $75 \%$ (red). Slope of each model is indicated as $\mathrm{b}$ and $\mathrm{R}$ squared values correspond to overall ANCOVA R squared for each variable at each variability scale. Different letters associated with the slopes indicate significant $(\mathrm{p}<0.05)$ differences versus control. 


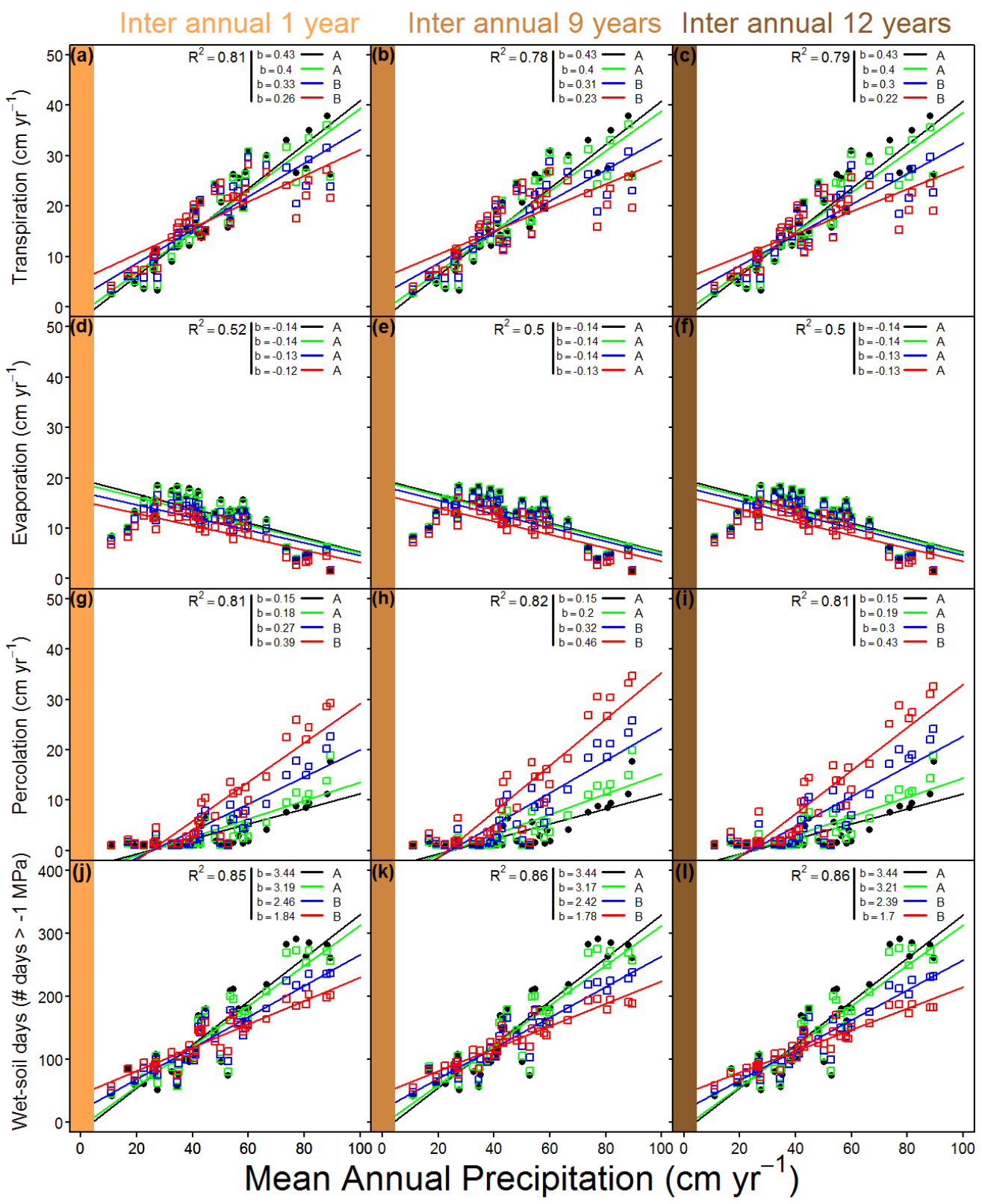


Table S2a Results for statistical analyses of mean transpiration and evaporation as a function of mean annual precipitation across increased variability treatments.

\section{Transpiration}

Intra-annual variability

Model Intercept

Control

\begin{tabular}{llll}
\hline Slope & SE & $\boldsymbol{t}$-value & $\boldsymbol{P}$ \\
\hline-2.523 & 1.63 & -1.55 & 0.124 \\
0.434 & 0.03 & 13.75 & $<0.001$
\end{tabular}

Contrasts of treatments to control

$25 \%$

$50 \%$

$75 \%$

0.03

13.75

$-0.002$

$0.05 \quad-0.05$

0.959

$-0.008$

$0.05 \quad-0.19$

0.852

$-0.007$

$0.05 \quad-0.15$

0.885

Model: $\mathrm{R}^{2}=0.85, F_{(7,132)}=106.4, P<0.001$.

1-year inter-annual variability

Model Intercept

$\begin{array}{llll}-2.523 & 1.59 & -1.58 & 0.116 \\ 0.434 & 0.03 & 14.05 & <0.001\end{array}$

Control

0.434

$0.03-14.05$

$-0.029$

$0.04 \quad-0.67$

0.504

$-0.104$

$\begin{array}{ll}0.04 & -2.39\end{array}$

0.018

$-0.176$

$0.04 \quad-4.03$

$<0.001$

Model: $\mathrm{R}^{2}=0.81, F_{(7,132)}=79.03, P<0.001$.

Evaporation

\begin{tabular}{llll}
\hline Slope & SE & $\boldsymbol{t}$-value & $\boldsymbol{P}$ \\
\hline 19.616 & 1.37 & 14.27 & $<0.001$ \\
-0.144 & 0.03 & -5.39 & $<0.001$
\end{tabular}

$\begin{array}{llll}.003 & 0.04 & 0.08 & 0.935 \\ .013 & 0.04 & 0.35 & 0.725 \\ .03 & 0.04 & 0.79 & 0.43\end{array}$

Model: $\mathrm{R}^{2}=0.43, F_{(7,132)}=14.42, P<0.001$.

$75 \%$

$\begin{array}{rrrr}19.616 & 1.26 & 15.55 & <0.001 \\ -0.144 & 0.02 & -5.87 & <0.001\end{array}$

$\begin{array}{llll}0.005 & 0.04 & 0.16 & 0.875\end{array}$

$\begin{array}{llll}0.017 & 0.04 & 0.49 & 0.628\end{array}$

$\begin{array}{llll}0.023 & 0.04 & 0.67 & 0.502\end{array}$ 
3-year inter-annual variability

$\begin{array}{lllllllll}\text { Model Intercept } & -2.523 & 1.61 & -1.57 & 0.118 & 19.616 & 1.29 & 15.21 & <0.001 \\ \text { Control } & 0.434 & 0.03 & 13.95 & <0.001 & -0.144 & 0.03 & -5.75 & <0.001\end{array}$

Contrasts of treatments to control

\begin{tabular}{lllllllll}
$25 \%$ & -0.036 & 0.04 & -0.81 & 0.418 & 0.004 & 0.04 & 0.11 & 0.912 \\
$50 \%$ & -0.126 & 0.04 & -2.85 & 0.005 & 0.013 & 0.04 & 0.38 & 0.705 \\
$75 \%$ & -0.203 & 0.04 & -4.61 & $<0.001$ & 0.019 & 0.04 & 0.53 & 0.595 \\
\hline
\end{tabular}

6-year inter-annual variability

$\begin{array}{lcccccccc}\text { Model Intercept } & -2.523 & 1.63 & -1.55 & 0.123 & 19.616 & 1.31 & 14.94 & <0.001 \\ \text { Control } & 0.434 & 0.03 & 13.78 & <0.001 & -0.144 & 0.03 & -5.65 & <0.001\end{array}$

Contrasts of treatments to control

\begin{tabular}{lllllllll}
$25 \%$ & -0.036 & 0.05 & -0.82 & 0.416 & 0.003 & 0.04 & 0.08 & 0.935 \\
$50 \%$ & -0.129 & 0.05 & -2.89 & 0.004 & 0.01 & 0.04 & 0.27 & 0.789 \\
$75 \%$ & -0.207 & 0.05 & -4.64 & $<0.001$ & 0.014 & 0.04 & 0.39 & 0.696 \\
\hline
\end{tabular}




\begin{tabular}{|c|c|c|c|c|c|c|c|c|}
\hline \multirow[b]{2}{*}{ 9-year inter-annual variability } & \multicolumn{4}{|c|}{ Transpiration } & \multicolumn{4}{|c|}{ Evaporation } \\
\hline & Slope & SE & $t$-value & $\boldsymbol{P}$ & Slope & SE & $t$-value & $\boldsymbol{P}$ \\
\hline Model Intercept & -2.523 & 1.66 & -1.52 & 0.132 & 19.616 & 1.33 & 14.80 & $<0.001$ \\
\hline Control & 0.434 & 0.03 & 13.46 & $<0.001$ & -0.144 & 0.03 & -5.59 & $<0.001$ \\
\hline \multicolumn{9}{|l|}{ Contrasts to control } \\
\hline $25 \%$ & -0.034 & 0.05 & -0.75 & 0.452 & 0.001 & 0.04 & 0.03 & 0.973 \\
\hline $50 \%$ & -0.124 & 0.05 & -2.72 & 0.007 & 0.007 & 0.04 & 0.19 & 0.853 \\
\hline $75 \%$ & -0.201 & 0.05 & -4.41 & $<0.001$ & 0.011 & 0.04 & 0.30 & 0.764 \\
\hline & $\begin{array}{l}\text { Model: } \mathrm{R}^{2} \\
0.001 .\end{array}$ & $=0.79$, & $132)=68$ & $P<$ & $\begin{array}{l}\text { Model: } \mathrm{R}^{2} \\
0.001 .\end{array}$ & 0.50 & $7,132)=18$ & $P<$ \\
\hline
\end{tabular}

12-year inter-annual variability

\begin{tabular}{|c|c|c|c|c|c|c|c|c|c|}
\hline & Model Intercept & -2.523 & 1.62 & -1.56 & 0.122 & 19.616 & 1.31 & 14.94 & $<0.001$ \\
\hline & Control & 0.434 & 0.03 & 13.80 & $<0.001$ & -0.144 & 0.03 & -5.65 & $<0.001$ \\
\hline \multicolumn{10}{|l|}{ Contrasts to control } \\
\hline & $25 \%$ & -0.036 & 0.04 & -0.81 & 0.418 & 0.003 & 0.04 & 0.07 & 0.944 \\
\hline & $50 \%$ & -0.131 & 0.04 & -2.94 & 0.004 & 0.009 & 0.04 & 0.26 & 0.798 \\
\hline & $75 \%$ & -0.212 & 0.04 & -4.76 & $<0.001$ & 0.014 & 0.04 & 0.40 & 0.693 \\
\hline & & \multicolumn{8}{|c|}{ Model: $\mathrm{R}^{2}=0.79, F_{(7,132)}=71.38, P<\quad$ Model: $\mathrm{R}^{2}=0.50, F_{(7,132)}=18.86, P<$} \\
\hline
\end{tabular}


Table S2b Results of statistical analyses of deep percolation and soil water content as a function of mean annual precipitation across increased variability treatments.

\section{Percolation}

Intra-annual variability

Model Intercept

Control

Contrasts of treatments to control

$25 \%$

$50 \%$

$75 \%$

\begin{tabular}{llll}
\hline Slope & SE & $t$-value & $\boldsymbol{P}$ \\
\hline-3.670 & 1.07 & -3.43 & 0.001 \\
0.150 & 0.02 & 7.22 & $<0.001$
\end{tabular}

Wet-soil days

\begin{tabular}{llll}
\hline Slope & SE & $\boldsymbol{t}$-value & $\boldsymbol{P}$ \\
\hline-14.308 & 12.74 & -1.12 & 0.264 \\
3.435 & 0.25 & 13.91 & $<0.001$
\end{tabular}

\begin{tabular}{cccccccc}
0.004 & 0.03 & 0.13 & 0.898 & -0.039 & 0.35 & -0.11 & 0.912 \\
0.019 & 0.03 & 0.65 & 0.518 & -0.162 & 0.35 & -0.46 & 0.644 \\
0.054 & 0.03 & 1.84 & 0.069 & -0.310 & 0.35 & -0.89 & 0.377 \\
\hline
\end{tabular}

1-year inter-annual variability

Model Intercept

$\begin{array}{llll}-3.670 & 1.24 & -2.97 & 0.004 \\ 0.150 & 0.02 & 6.25 & <0.001\end{array}$

$-14.308$

10.77

$-1.33$

0.186

Control

$\begin{array}{lll}0.150 & 0.02 & 6.25\end{array}$

3.435

0.21

16.45

$<0.001$

Contrasts of treatments to control

\begin{tabular}{|c|c|c|c|c|c|c|c|c|}
\hline $25 \%$ & 0.031 & 0.03 & 0.91 & 0.365 & -0.248 & 0.30 & -0.84 & 0.402 \\
\hline $50 \%$ & 0.117 & 0.03 & 3.46 & 0.001 & -0.977 & 0.30 & -3.31 & 0.001 \\
\hline $75 \%$ & 0.238 & 0.03 & 7.03 & $<0.001$ & -1.592 & 0.30 & -5.39 & $<0.001$ \\
\hline
\end{tabular}


3-year inter-annual variability

$\begin{array}{lllllllll}\text { Model Intercept } & -3.670 & 1.30 & -2.82 & 0.006 & -14.308 & 10.41 & -1.37 & 0.172 \\ \text { Control } & 0.150 & 0.03 & 5.93 & <0.001 & 3.435 & 0.20 & 17.02 & <0.001\end{array}$

Contrasts of treatments to control

\begin{tabular}{llllllllll}
$25 \%$ & 0.038 & 0.04 & 1.06 & 0.291 & -0.235 & 0.29 & -0.82 & 0.413 & -32 \\
$50 \%$ & 0.139 & 0.04 & 3.91 & $<0.001$ & -0.997 & 0.29 & -3.49 & 0.001 & -5.97 \\
$75 \%$ & 0.266 & 0.04 & 7.44 & $<0.001$ & -1.703 & 0.29 & -0.001 \\
\hline
\end{tabular}

6-year inter-annual variability

$\begin{array}{lccccccccc}\text { Model Intercept } & -3.670 & 1.38 & -2.66 & 0.009 & -14.308 & 10.27 & -1.39 & 0.166 \\ \text { Control } & 0.150 & 0.03 & 5.59 & <0.001 & 3.435 & 0.20 & 17.25 & <0.001\end{array}$

Contrasts of treatments to control

$\begin{array}{lllllllrrrr}25 \% & 0.048 & 0.04 & 1.26 & 0.21 & -0.265 & 0.28 & -0.94 & 0.349 \\ 50 \% & 0.162 & 0.04 & 4.29 & <0.001 & -1.084 & 0.28 & -3.85 & <0.001 \\ 75 \% & 0.297 & 0.04 & 7.85 & <0.001 & -1.718 & 0.28 & -6.10 & <0.001\end{array}$

Model: $\mathrm{R}^{2}=0.82, F_{(7,132)}=86.71, P<0.001 . \quad$ Model: $\mathrm{R}^{2}=0.86, F_{(7,132)}=111.86, P<0.001$.




\section{Percolation}

9-year inter-annual variability

Model Intercept

Control

Contrasts of treatments to control

$25 \%$

$50 \%$

$75 \%$

\begin{tabular}{llll}
\hline Slope & SE & $t$-value & $\boldsymbol{P}$ \\
\hline-3.670 & 1.41 & -2.60 & 0.01 \\
0.150 & 0.03 & 5.47 & $<0.001$
\end{tabular}

$0.053 \quad 0.04 \quad 1.38$

0.171

$\begin{array}{lll}0.172 & 0.04 \quad 4.45\end{array}$

$<0.001$

0.311

$0.04 \quad 8.02$

$<0.001$
Wet-soil days

\begin{tabular}{llll}
\hline Slope & SE & $t$-value & $\boldsymbol{P}$ \\
\hline-14.308 & 10.36 & -1.38 & 0.169 \\
3.435 & 0.20 & 17.11 & $<0.001$
\end{tabular}

$-0.263$

0.28

$-0.93$

0.357

$-1.011$

0.28

$-3.56$

0.001

$-1.655$

0.28

$-5.83$

$<0.001$ 12-year inter-annual variability

Model Intercept

Model: $\mathrm{R}^{2}=0.86, F_{(7,132)}=111.45, P<0.001$.

Control

$\begin{array}{llll}-3.670 & 1.38 & -2.65 & 0.009 \\ 0.150 & 0.03 & 5.59 & 0\end{array}$

$-14.308$

10.25

3.435

0.20

$-1.40$

0.165

Contrasts of treatments to control

\begin{tabular}{llllllllll}
$25 \%$ & 0.040 & 0.04 & 1.05 & 0.294 & -0.223 & 0.28 & -0.79 & 0.429 \\
$50 \%$ & 0.149 & 0.04 & 3.93 & 0 & -1.048 & 0.28 & -3.73 & 0 \\
$75 \%$ & 0.278 & 0.04 & 7.34 & 0 & -1.737 & 0.28 & -6.18 & 0 \\
\hline
\end{tabular}

